Bull. Mater. Sci., Vol. 22. No. 2. April 1999, pp. 89-94. (O Indian Academy of Sciences.

\title{
Influence of metal particles on the reduction properties of ceria-based materials studied by TPR
}

\author{
G RANGA RAO \\ Department of Chemistry, Indian Institute of Technology, Chennai 600036 , India \\ MS received 17 October 1998; revised 2 February 1999
}

\begin{abstract}
Temperature programmed reduction (TPR) investigations on ceria-based catalytic materials are presented. Pure ceria shows two major reduction regions around $790 \mathrm{~K}$ and $1100 \mathrm{~K}$ due to surface capping oxygen ions and bulk oxygen ions. The extent of reduction in the low temperature region depends greatly on the surface area of the sample. The remnant reduction features that appear below $700 \mathrm{~K}$ are ascribed to $\mathrm{O}^{2-}$ ions located at various low coordination sites on the oxide crystallites. The substitution of $\mathrm{ZrO}_{2}$ $(40-60 \%)$ in $\mathrm{CeO}_{2}$ lattice decreases the overall reduction temperature of high surface area samples. Metal particles supported on Jow surface area $\mathrm{CeO}_{2}-\mathrm{ZrO}_{2}$ solid solutions induce bulk reduction of the support at low temperatures to a great extent. These observations provide a clue that the $\mathrm{CeO}_{2}$-based oxide supports, irrespective of their surface area, can perform as good oxygen exchangers in the presence of metal particles, contributing indirectly to the overall catalytic activity.
\end{abstract}

Keywords. TPR; reduction; ceria-based materials; metal particles.

\section{Introduction}

Ceria-based materials have been increasingly investigated for the past several years due to their potential applications in many catalytic processes (Yao and Yao 1984; Harrison et al 1988; Ranga Rao et al 1994, 1996; Brogan et al 1995; Idriss et al 1995; Xu and Iglesia 1998). One of the important areas of ceria application today is depollution catalysis (Trimm et al 1996; Fornasiero et al 1998; Kondarides et al 1998). A number of research articles have been published in the literature discussing about the possible role of ceria in the exhaust and several other catalytic processes (Trovarelli 1996; Kundakovic and Stephanopoulos 1998). Ceria is added to the exhaust catalyst ( $\mathrm{Pt}$ or $\mathrm{Pd}, \mathrm{Rh}$ deposited on $\mathrm{Al}_{2} \mathrm{O}_{3}$ ) up to about 25 wt\%. It is known to amplify the activity of many catalysts. For example, the contribution of ceria is very important in steam reforming, water gas shift and NO reduction reactions over metal catalysts. It is noted that $\mathrm{Ni}$ supported on $\mathrm{CeO}_{2}$ is about 20 times more active than $\mathrm{Ni}$ supported on $\mathrm{SiO}_{2}$ in steam reforming (Herrmann et al 1989; Barrault et al 1991). These conclusive observations may be explained in terms of ceria-metal interactions induced by reduction treatment/atmosphere and we sought to investigate this aspect in ceria-based catalytic systems using temperature programmed reduction method.

\footnotetext{
*Author for correspondence
}

Temperature programmed reduction (TPR) is a simple thermal technique that has been extensively used, besides many others, to investigate ceria-based materials (Yao and Yao 1984; Laachir et al 1991; Trovarelli et al 1992; Ranga Rao et al 1995). The principle of TPR is that a dilute mixture of $\mathrm{H}_{2}(5-6 \%)$ in an inert gas such as $\mathrm{N}_{2}$ or At is passed through one arm of a thermal conductivity detector (TCD) and then over the solid material and finally through the second arm of the TCD. The solid material is subjected to linear heating at a preset ramp rate during the experiment. Consumption of $\mathrm{H}_{2}$ due to the reduction of solid sample is recorded from the out-of-balance signal produced by the detector wires with mismatching temperatures in the Wheatstone bridge. The outcome of such an experiment is the TPR profile which is a plot of TCD signal $\left(\mathrm{H}_{2}\right.$ consumed $)$ versus the temperature of the solid sample. The TPR profile can provide wealth of information about the redox properties of oxide materials, valence states of metal ions at various stages of reduction, oxide catalyst composition, temperatures ( $T_{\max }$ values) at which the catalyst material could be sensitive to the reaction mixture, oxide crystallite size, surface area and the nature of metal-support interactions. This method can also be applied to estimate oxygen storage capacities of ceria and the atomic oxygen deposited on catalyst materials by the decomposition of nitrous oxide $\left(\mathrm{N}_{2} \mathrm{O}\right.$ ), nitric oxide (NO) and $\mathrm{O}_{2}$ (Bond and Namijo 1989; Fornasiero et al 1995). The kinetics of reduction can in principle be used to obtain information on the nature of metal (mono-, bi- and multi-metallic) 
particles, oxide support and the type of interactions that exist between them. In this paper, we shall critically look at the reduction profiles of ceria and ceria-based binary oxide materials and the effect of metallic particles on them.

\section{Experimental}

Low and high surface area $\mathrm{CeO}_{2}$ and $\mathrm{CeO}_{2}-\mathrm{ZrO}_{2}$ solid solutions were prepared by ceramic and precursor methods, respectively, as reported elsewhere (Ranga Rao et al 1995; Fornasiero et al 1996). The BET surface areas were measured by $\mathrm{N}_{2}$ adsorption at $77 \mathrm{~K}$ on a Micromeritics surface area analyzer. Powder X-ray diffraction pattern showed the formation of oxide phases indicated in the text (Nagarajan and Rao 1991). Supports were impregnated with $\mathrm{RhCl}_{3} 3 \mathrm{H}_{2} \mathrm{O}$ (0.5\% loading) to incipient wetness and then dried at $393 \mathrm{~K}$. The dried samples were calcined at 523 or $723 \mathrm{~K}$ for $4-5 \mathrm{~h}$. TPR was carried out in a conventional system equipped with a TCD detector in flow of $5 \% \mathrm{H}_{2}$ in $\operatorname{Ar}\left(20 \mathrm{ml} \mathrm{min}^{-1}\right)$.

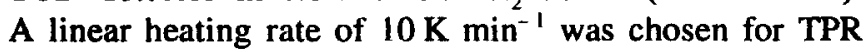
measurements. The catalyst sample $(\sim 40 \mathrm{mg})$ was loaded in a U-shaped microreactor and the temperature was monitored by a thermocouple located in the sample bed.

\section{Results and discussion}

\subsection{TPR of $\mathrm{CeO}_{2}$ samples}

Figure 1 shows TPR profiles of pure ceria samples of three different surface areas. Ceria reduction takes place essentially in two temperature regions. The first region is $573-873 \mathrm{~K}$ with $T_{\max }$ around $790 \mathrm{~K}$ and the second region is $973-1273 \mathrm{~K}$ with $T_{\max }$ around $1100 \mathrm{~K}$. These two reduction regions are characteristic of ceria and attributed to surface and bulk reduction processes, respectively (Yao and Yao 1984; Johnson and Mooi 1987; Bruce et al 1996). The unsaturated surface capping oxygen ions are removed as $\mathrm{H}_{2} \mathrm{O}$ rather easily in the low temperature region. However, bulk oxygen requires to be transported to the surface before their reduction to $\mathrm{H}_{2} \mathrm{O}$. This process, therefore, occurs in the high temperature region. Another important aspect to be noticed is that the hydrogen consumption in the low temperature region increases with surface area of the ceria sample. This observation is consistent with the earlier report (Perrichon et al 1994) in which a linear correlation has been found between the surface area and the amount of hydrogen consumed in the low temperature region. The small but significant reduction shoulders seen as minor low temperature peaks in figure 1 indicate the presence of surface oxygen ions that are reducible at lower temperatures than $T_{\max }, 790 \mathrm{~K}$. The presence of variety of surface capping oxygen ions can be expected by con- sidering a small $\mathrm{CeO}_{2}$ crystallite. The crystallite surface may contain $\mathrm{O}^{2-}$ ions at different positions with varied coordination numbers. For example, the oxide surface can have imperfections such as steps, kinks, corners and faces projecting $\mathrm{O}^{2-}$ ions of different coordination numbers (Dyrek and Che 1997). The variety and population of such surface $\mathrm{O}^{2-}$ ions may increase with surface area. The reactivity of these $\mathrm{O}^{2-}$ ions in different crystallite framework positions also varies accordingly. It can therefore be predicted that $\mathrm{O}^{2-}$ ions with less coordination would be reduced at lower temperature than those with higher coordination. This prediction explains qualitatively the presence of different reduction shoulders to the peak in the low temperature region.

Figure 2 shows the TPR profiles of calcined $\mathrm{CeO}_{2}$ samples with $0.5 \% \mathrm{Rh}$ loading. The profiles compare the reduction process of ceria samples of different surface areas in the presence of dispersed rhodium oxide particles. It is clear that the extent of reduction occurring between $325-425 \mathrm{~K}$ is progressively increasing with the surface area of $\mathrm{CeO}_{2}$ support. We also see a shift in the peak maximum by $\sim 50 \mathrm{~K}$ from low to high surface area samples. These results indicate that the magnitude of

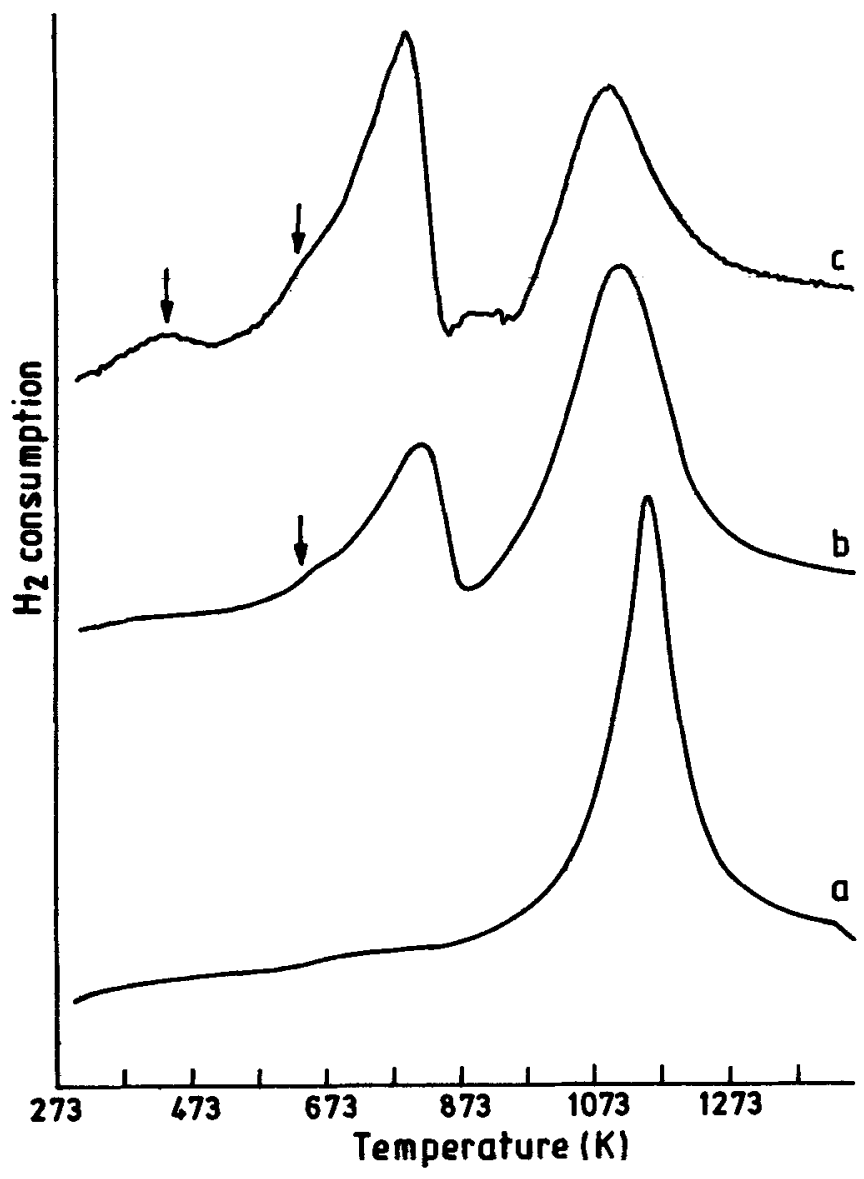

Figure 1. TPR profiles of $\mathrm{CeO}_{2}$ samples with surface areas: (a) $1.5 \mathrm{~m}^{2} / \mathrm{g}$, (b) $30 \mathrm{~m}^{2} / \mathrm{g}$ and (c) $130 \mathrm{~m}^{2} / \mathrm{g}$. 
ceria reduction depends on two factors: (i) surface area of ceria and (ii) metal-ceria interactions. When the surface area of $\mathrm{CeO}_{2}$ is increased, the amount of surface oxygen also increases accordingly as noted in figure 1 . Further, the metal particle associated with $\mathrm{CeO}_{2}$ crystallite decreases the reduction temperature of surface oxygen species from $790 \mathrm{~K}$ to $\sim 400 \mathrm{~K}$ by promoting the reduction process efficiently. The underlying mechanism of this process is the spill over of hydrogen from metal to ceria crystallite (Ranga Rao et al 1994). Since the low surface area $\left(\sim 1 \mathrm{~m}^{2} / \mathrm{g}\right) \mathrm{CeO}_{2}$ sample has negligible amount of surface oxygen (see profile a in figure 1), the small reduction peak at $350 \mathrm{~K}$ in figure 2 is ascribed to the reduction of rhodium oxide alone. The $\sim 50 \mathrm{~K}$ peak-shift in each case can reasonably be attributed to $\mathrm{Rh}-\mathrm{CeO}_{2}$ interaction which is expected to increase with the surface area of $\mathrm{CeO}_{2}$ and better $\mathrm{Rh}$ dispersion in the samples. It is rather difficult to determine unambiguously whether the $\mathrm{Rh}-\mathrm{CeO}_{2}$ interaction is electronic or physical in nature. However, the increase in surface area would create larger interface between $\mathrm{CeO}_{2}$ crystallite and $\mathbf{R h}$ metal particle and the magnitude of physical contact may turn out to be an important factor. Considering the TPR profiles in figure 2 , it appears that the physical interaction is responsible for the observed $\sim 50 \mathrm{~K}$ peakshifts. TPD measurements on $\mathrm{Rh} / \mathrm{CeO}_{2}$ under UHV conditions (Zafiris and Gorte 1993) show clear evidence for specific $\mathrm{Rh}-\mathrm{CeO}_{2}$ interaction that is responsible for surface oxygen migration from $\mathrm{CeO}_{2}$ to $\mathrm{Rh}$. The migrated oxygen can react with adsorbates such as $\mathrm{CO}$ or $\mathrm{H}_{2}$ at $\sim 400 \mathrm{~K}$. Therefore, both $\mathrm{Rh}-\mathrm{CeO}_{2}$ interaction and oxygen migration to metal (or hydrogen spill over to oxide) are responsible for the observed low temperature reduction under TPR conditions. The broad peak above $950 \mathrm{~K}$ is due to bulk reduction facilitated by oxygen vacancy defects.

\subsection{TPR of $\mathrm{CeO}_{2}-\mathrm{ZrO}_{2}$ samples}

The TPR profiles of three high surface area $\mathrm{CeO}_{2}-\mathrm{ZrO}_{3}$ solid solutions are compared with the TPR profile of $\mathrm{CeO}_{2}$ in figure 3. The oxide solid solutions undergo reduction in the region between 500 and $950 \mathrm{~K}$ with different $T_{\max }$ values. Two important aspects should be noted in these TPR curves. One is that the solid solutions undergo maximum reduction at temperatures close to that of the $T_{\max }$ of $\mathrm{CeO}_{2}$ at $790 \mathrm{~K}$. The second aspect is that the surface and bulk oxygen TPR signatures, clearly seen in $\mathrm{CeO}_{2}$ TPR, are merged together in the solid solutions. This suggests that the whole ceria component, including bulk part, in the solid solutions is subjected to reduction in a single stage. There are small reduction shoulders that may account for the initiation of reduction process of the surface oxygen ions. The single stage reduction of solid solutions can be explained in terms of facile migration of oxygen ions in the $\mathrm{CeO}_{2}-\mathrm{ZrO}_{2}$ lattice (Murota et al 1993). The variation in $T_{\max }$ values seems to be related to the $\mathrm{ZrO}_{2}$ content in the sample and may have some structural dependency as well (Ranga Rao et al 1995).

The three high surface area oxide solid samples, discussed above, have been used for $0.5 \% \mathrm{Rh}$ loading. The TPR profiles of $\mathrm{Rh}$ loaded and calcined samples are shown in figure 4 . The ceria component in all the solid solutions is completely reduced below $500 \mathrm{~K}$ while the bulk of the pure $\mathrm{CeO}_{2}$ sample required higher temperatures up to $1100 \mathrm{~K}$. It is also interesting to observe that the solid solutions are reduced at about $90 \mathrm{~K}$ lower than pure $\mathrm{CeO}_{2}$ in the presence of $\mathrm{Rh}$. The TPR results suggest that complete reduction of solid solutions has occurred at temperatures lower than that of the pure ceria. This is a significant and useful result if the ceria-based catalysts were to be employed to work under low temperature conditions.

Figure 5 displays the TPR profiles of low surface area ceria and $\mathrm{Ce}_{0.6} \mathrm{Zr}_{0.4} \mathrm{O}_{2}$ solid solution samples with and without rhodium metal. The reduction of pure ceria

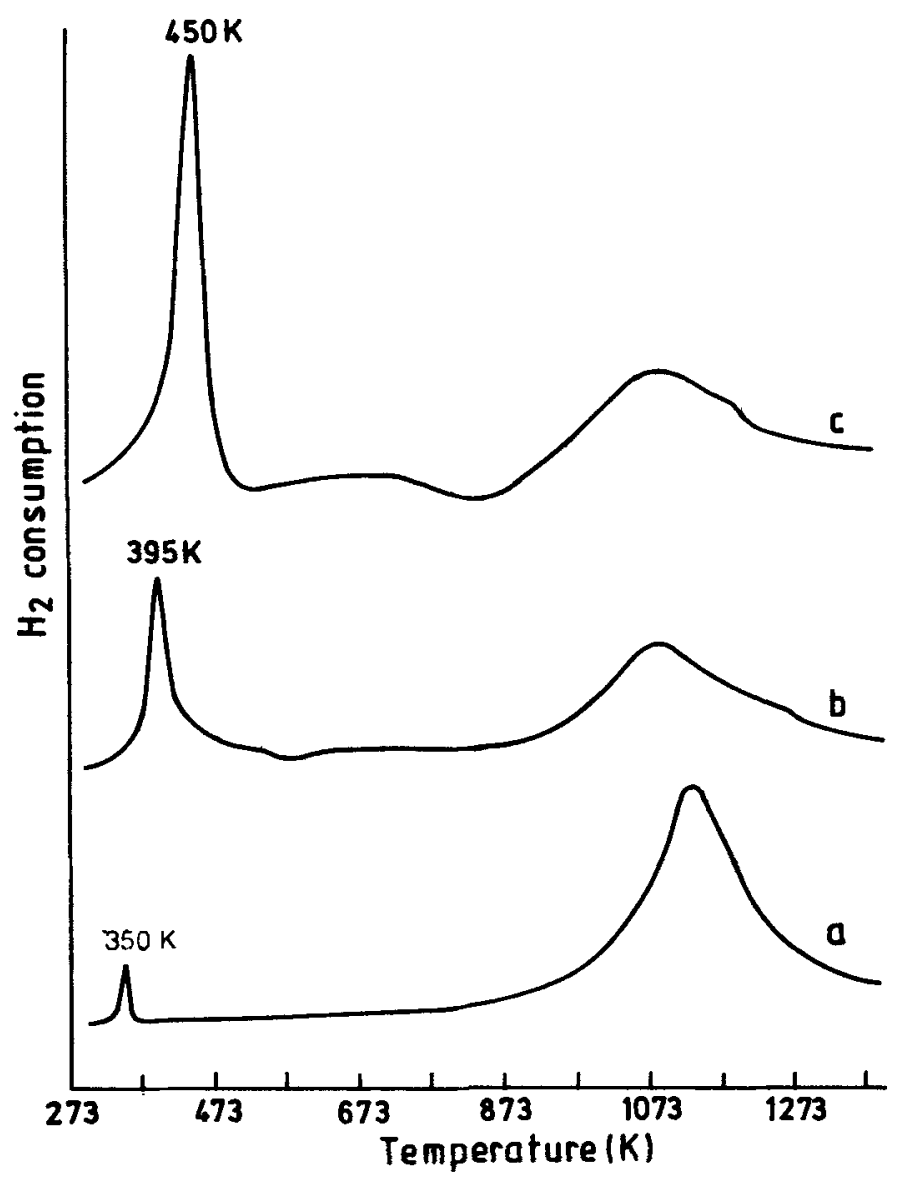

Figure 2. TPR profiles of calcined $0.5 \% \mathrm{Rh} / \mathrm{CeO}_{2}$ samples with $\mathrm{CeO}_{2}$ surface areas: (a) $1.5 \mathrm{~m}^{2} / \mathrm{g}$, (b) $30 \mathrm{~m}^{2} / \mathrm{g}$ and (c) $130 \mathrm{~m}^{2} / \mathrm{g}$. 
occurs above $1000 \mathrm{~K}$ as expected. Metallized ceria is seen to undergo reduction at slightly lower temperature. The small sharp peak at $340 \mathrm{~K}$ is due to the reduction of supported $\mathrm{Rh}_{2} \mathrm{O}_{3}$ particles. $\mathrm{ZrO}_{2}$ substitution in $\mathrm{CeO}_{2}$ does not seem to affect the reduction process of the low surface area $\mathrm{Ce}_{0.6} \mathrm{Zr}_{0.4} \mathrm{O}_{2}$ sample as the reduction of ceria component occurs above $950 \mathrm{~K}$ in the solid solution without rhodium metal. However, the presence of rhodium metal makes a lot of difference in the reduction process in the oxide solid solution. There is a strong reduction feature seen in the range 500-800 K when TPR is carried out on low surface area $\mathrm{Ce}_{0.6} \mathrm{Zr}_{0.4} \mathrm{O}_{2}$ in the presence of $\mathrm{Rh}$. The magnitude of reduction is so high that it cannot account for the reduction of surface oxygen alone. It is well known that $\mathrm{ZrO}_{2}$ does not get reduced below $1000 \mathrm{~K}$ and hence bulk reduction of $\mathrm{Ce}_{1+.6} \mathrm{Zr}_{01 \cdot 4} \mathrm{O}_{2}$ must have taken place to some extent (Ranga Rao et al 1995). This is an important observation due to the fact that ceria reduction is promoted by $\mathrm{Rh}$ metal at fairly low temperatures when substituted with $\mathrm{ZrO}_{2}$. It is difficult to reduce low surface area pure ceria sample, otherwise. Therefore, $\mathrm{ZrO}_{2}$ substituted ceria materials can be easily reduced/oxidized at low temperatures in the presence of metals, irrespective of their surface areas. These materials must be suitable as supports for low temperature as well as high temperature applications such as in exhaust catalysts and expected to show good oxygen storage capacities due to the bulk reduction (Fornasiero et al 1995). The support contribution to catalytic process would be significant in terms of oxygen exchange, even if it looses surface area due to sintering. Such a contribution may not be significant when $\mathrm{Al}_{2} \mathrm{O}_{3}-\mathrm{CeO}_{2}$ materials are used for catalyst preparation (Yao et al 1997).

\subsection{Probable reduction mechanism}

The above observations on the reducibility of ceria samples are in general agreement with reported results of X-ray photoemission, X-ray absorption and 'H-NMR experiments (Normand et al 1988; Laachir et al 1991; Fallah et al 1994; Pfau et al 1996). Pure $\mathrm{CeO}_{2}$ exists in fluorite structure and is difficult to reduce below

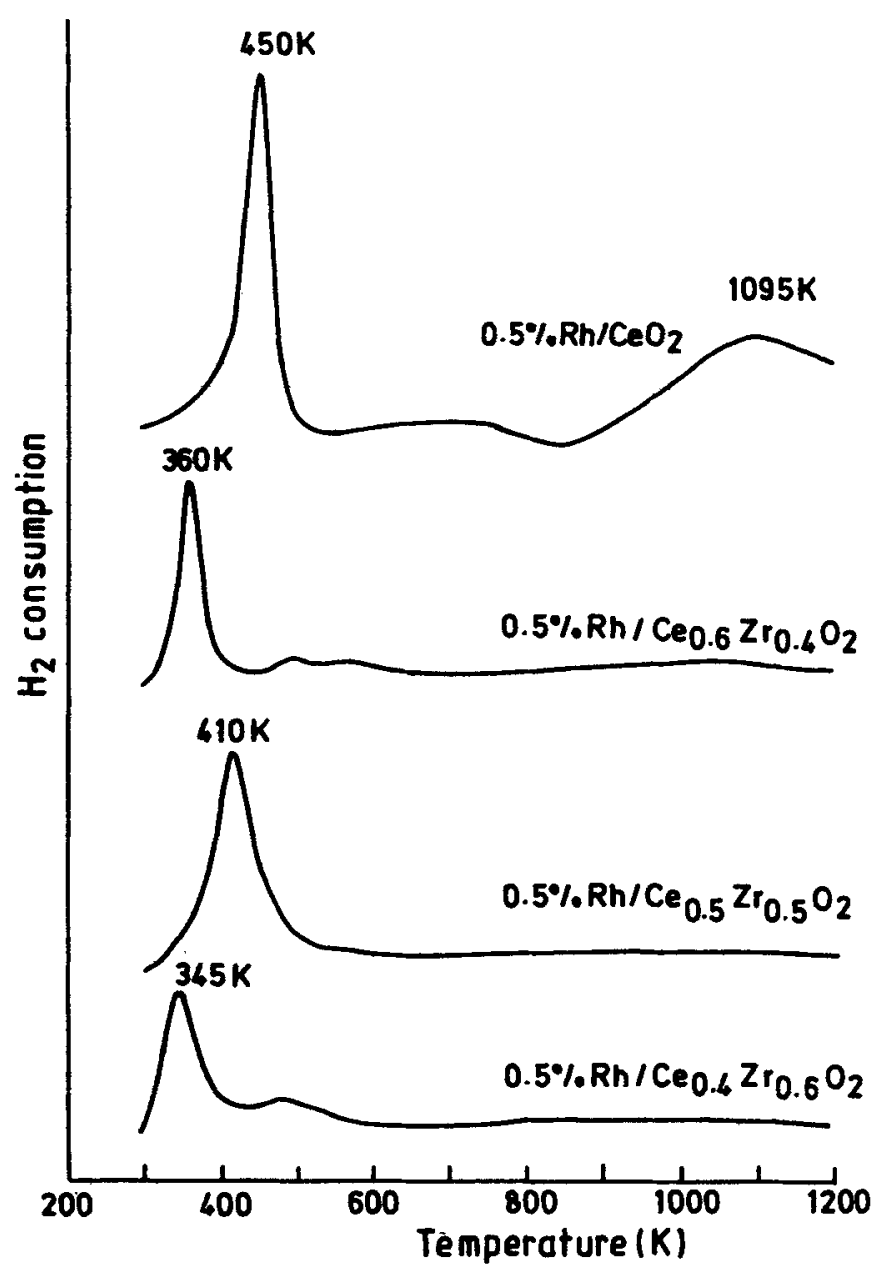

Figure 4. TPR profiles of calcined $0.5 \% \quad \mathrm{Rh} / \mathrm{CeO}_{2}-\mathrm{ZrO}_{2}$ samples with supports mentioned in figure 3 .
Figure 3. TPR profiles of $\mathrm{CeO}_{2}-\mathrm{ZrO}_{2}$ solid solutions in com-
parison to that of $\mathrm{CeO}_{2}:$ (a) $75 \mathrm{~m}^{2} / \mathrm{g}$, (b) $98 \mathrm{~m}^{2} / \mathrm{g}$, (c) $60 \mathrm{~m}^{2} / \mathrm{g}$

Figure 3. TPR profiles of $\mathrm{CeO}_{2}-\mathrm{ZrO}_{2}$ solid solutions in com-
parison to that of $\mathrm{CeO}_{2}:$ (a) $75 \mathrm{~m}^{2} / \mathrm{g}$, (b) $98 \mathrm{~m}^{2} / \mathrm{g}$, (c) $60 \mathrm{~m}^{2} / \mathrm{g}$ and (d) $130 \mathrm{~m}^{2} / \mathrm{g}$.

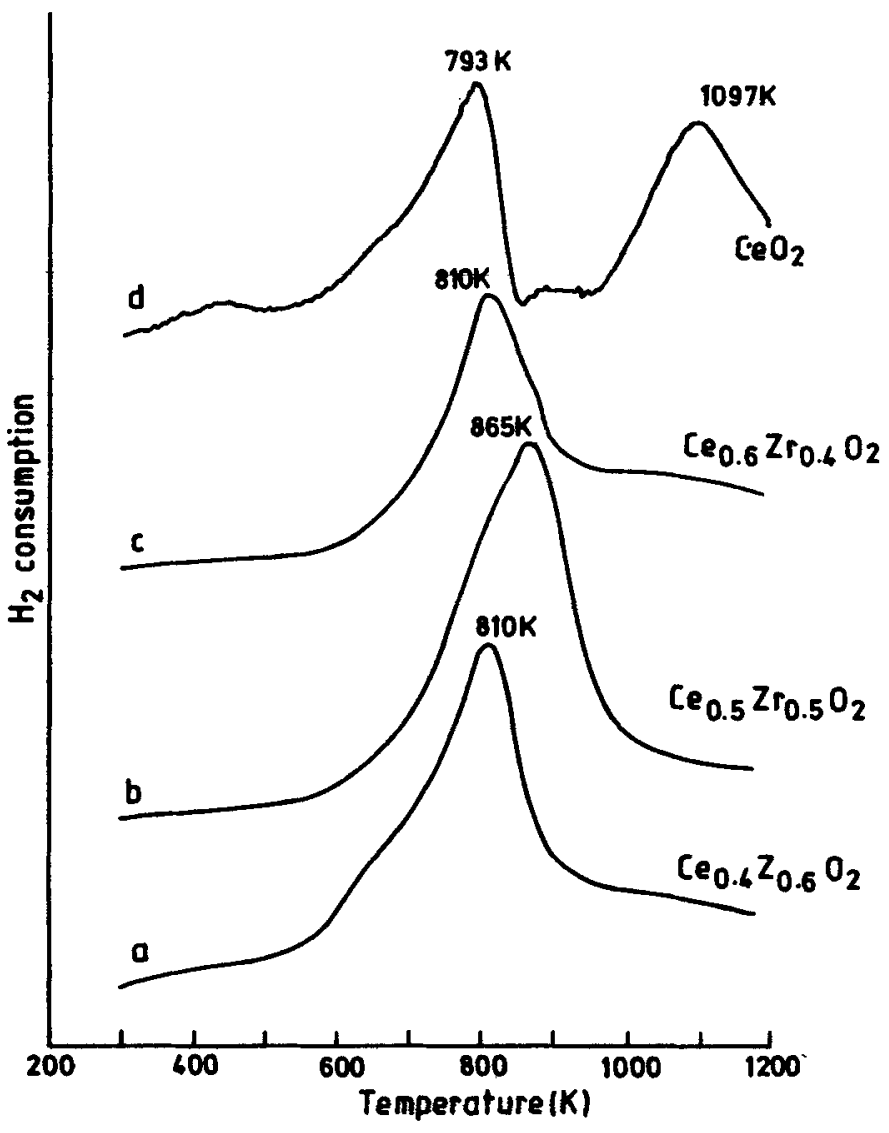




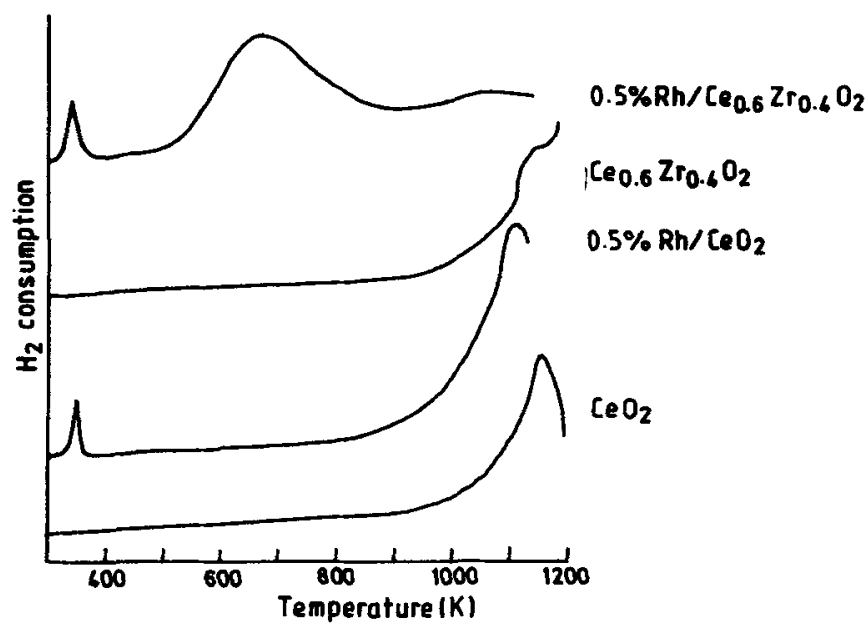

Figure 5. TPR profiles of low surface area $\left(\sim 1 \mathrm{~m}^{2} / \mathrm{g}\right)$ samples.

$600 \mathrm{~K}$ or under mild reducing conditions. However, the reducibility of ceria is enhanced significantly with dopants such as $\mathrm{ZrO}_{2}, \mathrm{HfO}_{2}$ and in the presence of transition metals as well (Cunningham et al 1990). The reduction mechanism of ceria-based materials is essentially related to the kinetic model proposed for pure ceria reduction (Fallah et al 1994). The reduction of $\mathrm{CeO}_{2}$ and $\mathrm{Ce}_{x} \mathrm{Zr}_{1}, \mathrm{O}_{2}$ occurs due to the direct dissociative chemisorption of $\mathrm{H}_{2}$ on surface site leading to the formation of water via hydroxyl groups followed by the creation of surface oxygen vacancies and reduction of $\mathrm{Ce}^{4+}$ ions to $\mathrm{Ce}^{3+}$ ions. This can be written as

$$
2 \mathrm{H}_{\mathrm{aJ}}+2 \mathrm{Ce}^{4+}+\mathrm{O}^{2-} \rightarrow 2 \mathrm{Ce}^{3+}+\mathrm{H}_{2} \mathrm{O}+\square,
$$

where $\square$ is a surface oxygen vacancy. The 'H-NMR signals show evidence for hydrogen atoms chemisorbed on $\mathrm{CeO}_{2}$ as well as on metal atoms while the HeI UV photoemission spectra with bands at 7.0 and $10.7 \mathrm{eV}$ indicate the generation of surface $\mathrm{OH}$ groups (Pfau et al 1996). Therefore, surface reduction is more pronounced in the first stage of reduction process and is evidently influenced by the surface area of the samples (see the TPR curves in figure 1). The diffusion of surface anion vacancies into the bulk ceria occurs at relatively high temperature contributing to slow bulk reduction. In the case of $\mathrm{Ce}_{x} \mathrm{Zr}_{1-x} \mathrm{O}_{2}$ samples, both surface and bulk reduction occur simultaneously (see figure 3 ) due to the increased oxygen mobility in the defective fluorite structure. However, the presence of metal strongly modifies the reduction kinetics causing the oxide reduction around $350-400 \mathrm{~K}$. This is the result of $\mathrm{Rh}$ metal participation in hydrogen dissociation and rapid supply of $\mathrm{H}$ atoms to support oxide by the spill-over process. This mechanism favours the high rate of formation of water and oxygen vacancy sites on both $\mathrm{CeO}_{2}$ and $\mathrm{Ce}_{x} \mathrm{Zr}_{1-x} \mathrm{O}_{2}$ oxide surfaces even at very low temperatures. The complete reduction of $\mathrm{Ce}_{x} \mathrm{Zr}_{1-x} \mathrm{O}_{2}$ samples in the presence of $\mathrm{Rh}$ metal at low temperatures is facilitated by hydrogen spill-over as well as high oxygen ion mobility in the solid solutions.

\section{Conclusions}

The following conclusions can be drawn from the TPR results discussed in this paper. Ceria undergoes reduction according to the reaction, $2 \mathrm{CeO}_{2}+\mathrm{H}_{2} \rightarrow \mathrm{Ce}_{2} \mathrm{O}_{3}+\mathrm{H}_{2} \mathrm{O}$. Reduction occurs in two distinct temperature regions except when the surface area is very less $\left(\sim 1 \mathrm{~m}^{2} / \mathrm{g}\right)$. The low temperature reduction is enhanced with surface area of ceria. The substitution of $\mathrm{ZrO}_{2}$ in ceria affects the reduction properties drastically. Rhodium metal promotes the reduction of both pure ceria and $\mathrm{CeO}_{2}-\mathrm{ZrO}_{2}$ solid solutions. The promotion effect of $\mathrm{Rh}$ is more predominant in the high surface area solid solutions which undergo almost complete reduction at temperatures as low as $350 \mathrm{~K}$. Ceria reduction occurs in two steps: (i) first one is the extraction of surface capping $\mathrm{O}^{2-}$ ions by chemisorbed $\mathrm{H}$ atoms creating anion vacancies, (ii) the second step is the diffusion of surface anion vacancies into the bulk. Support reduction takes place at faster rate in the presence of metal particles due to hydrogen spillover. The promotional effect of $\mathrm{Rh}$ and the presence of $\mathrm{ZrO}_{2}$ content would certainly furnish better reduction and oxygen exchange properties to ceria, making it a more attractive material for exhaust applications, particularly in cold start conditions.

\section{Acknowledgements}

The author would like to thank his collaborators whose names appeared in some of the references cited in this paper. The financial support provided by CSIR, New Delhi, is gratefully acknowledged.

\section{References}

Barrault J, Chafik A and Gallezot P 1991 Appl. Catal. 67257 Bond G C and Namijo S N 1989 J. Catal. 118507

Brogan M S, Caims J A, Dines T J and Rochester C H 1995 J. Chem. Soc. Faraday Trans. 91733

Bruce L A, Hoang M, Hughes A E and Turney T W 1996 Appl. Catal. A: General 134351

Cunningham J, O'Brien S, Sanz J, Rojo J M, Soria $J$ A and Fierro J L G 1990 J. Mol. Catal. 57379

Dyrek K and Che M 1997 Chem. Rev. 97305

Fallah J El, Boujana S, Dexpert H, Kiennemann A, Majerus J, Touret O, Villain F and Normand F Le 1994 J. Phys. Chem. 985522

Formasiero P, Di Monte R, Ranga Rao G, Kaspar J, Meriani S, Trovarelli $\AA$ A and Graziani M 1995 J. Catal. 151168

Fornasiero P, Balducci G, Di Monte R, Kaspar J, Sergo V, Gubitosa G, Ferrero A and Graziani M 1996 J. Catal. 164173 Fornasiero P, Ranga Rao G, Kaspar J, L'Erario $F$ and Graziani M 1998 J. Catal. 175269 
Harrison B, Diwell A G and Hallett C 1988 Platinum Metals Rev. 3273

Herrmann J M, Ramaroson E, Tempere J F and Guilleux M F 1989 Appl. Catal. 53117

Idriss H, Diagne C, Hindermann J P, Kiennemann A and Barteau M A 1995 J. Catal. 155219

Johnson M F L and Mooi J 1987 J. Catal. 103502

Kondarides D I, Zhang Z and Verykios X E 1998 J. Catal. 176536

Kundakovic Lj and Stephanopoulos M F 1998 Appl. Catal. A. General 17113

Laachir A et al 1991 J. Chem. Soc. Faraday Trans. 871601

Murota T, Hasegawa T, Aozasa S, Matsui $\mathbf{H}$ and Motoyama M $1993 \mathrm{~J}$. Alloys and Comp. 193298

Nagarajan V S and Rao K J 1991 J. Mater. Res. 62688

Normand F L, Hilaire L, Kili K, Krill G and Maire G 1988 J. Phys. Chem. 922561

Perrichon V, Laachir A, Bergeret G, Frety R, Toumayan L and Touret O 1994 J. Chem. Soc. Faraday Trans. 90773
Pfau A, Sanz J, Schierbaum, Gòpel W, Belzuncgui J P and Rojo J M 1996 Stud. Surf. Sci. Catal. 101931

Ranga Rao G, Kaspar J, Di Monte R, Meriani S and Graziani M 1994 Catal. Letts. 24107

Ranga Rao G, Fomasiero P, Kaspar J, Meriani S, Di Monte R and Graziani M 1995 Stud. Surf. Sci. Catal. 96631

Ranga Rao $\mathrm{O}$ et al $1996 \mathrm{~J}$. Catal. 1621

Trimm D L, Padeste C, Pettigrew D J. Whittington B and Cant N W 1996 Surface science: Principles and current applications (eds) R J MacDonald, E C Taglauer and K R Wandelt (Berlin: Springer) pp 363-372

Trovarelli A 1996 Catal. Rev. Sci. Eng. 38439

Trovarelli A, Dolcetti G, Leitenburg C, Kaspar J. Finetti P and Santoni A $1992 \mathrm{~J}$. Chem. Soc. Faraday Trans. 881311

Xu M and Iglesia E 1998 Catal. Letts. 5147

Yao H C and Yu Yao Y F 1984 J. Catal. 86254

Yao M H, Baird R J, Kunz F W and Hoost T E 1997 J. Catal. 16667

Zafiris G S and Gorte R J 1993 J. Catal. 139561 